\title{
Prevalence of Asthma Characteristics in COPD Patients in a Dutch Well-Established Asthma/ COPD Service for Primary Care
}

This article was published in the following Dove Press journal: International Journal of Chronic Obstructive Pulmonary Disease

\author{
Anna Jetske Baron (D) ${ }^{1-3}$ \\ Bertine MJ Flokstra- \\ de Blok iD 1,2,4 \\ Ellen van Heijst ${ }^{2,5}$ \\ Roland A Riemersma iD ${ }^{6}$ \\ Agnes MM Sonnenschein-van \\ der Voort ${ }^{7}$ \\ Esther I Metting (D) 2,6 \\ Janwillem WH Kocks (D) 1,2,8 \\ 'General Practitioners Research \\ Institute, Groningen, the Netherlands; \\ ${ }^{2}$ University of Groningen, University \\ Medical Center Groningen, GRIAC \\ Research Institute, Groningen, the \\ Netherlands; ${ }^{3}$ Department of Pulmonary \\ Diseases and Tuberculosis, University \\ Medical Center Groningen, Groningen, \\ the Netherlands; ${ }^{4}$ Department of \\ Pediatric Pulmonology and Pediatric \\ Allergology, University of Groningen, \\ University Medical Center Groningen, \\ Beatrix Children's Hospital, Groningen, \\ the Netherlands; ${ }^{5}$ Astma/COPD Dienst, \\ CERTE Laboratories, Groningen, the \\ Netherlands; ${ }^{6}$ Department of General \\ Practice and Elderly Care Medicine, \\ University of Groningen, University \\ Medical Center Groningen, Groningen, \\ the Netherlands; ${ }^{7}$ GlaxoSmithKline, \\ Zeist, the Netherlands; ${ }^{8}$ Observational \\ and Pragmatic Research Institute, \\ Singapore
}

Correspondence: Anna Jetske Baron Email annajetske@gpri.nl

\begin{abstract}
Purpose: Primary care COPD guidelines indicate that COPD patients with asthma characteristics should be treated as having asthma. This study aims to describe the prevalence of asthma characteristics in patients with a pulmonologist-confirmed working diagnosis of COPD or ACO.
\end{abstract}

Patients and Methods: This retrospective cross-sectional study used real-life data (collected between 2007 and 2017) from a Dutch asthma/COPD-service, a structured web-based system in which pulmonologists support general practitioners in their diagnosis of patients with suspicion of obstructive lung disease. The prevalence of asthma characteristics (history of asthma, atopy, symptoms, and reversibility) and blood eosinophil (Eos) counts were assessed in patients with a working diagnosis of COPD or ACO.

Results: Of the 14,141 patients, $\geq 40$ years in the dataset, 4475 (31.6\%) were diagnosed with asthma, 3532 (25.0\%) with COPD, and $1276(9.0 \%)$ with ACO. Asthma characteristics were present in $65.6 \%(n=1956)$ of the COPD and $90.9 \%(n=1059)$ of the ACO patients. Eos counts of $\geq 300$ cells per $\mu \mathrm{L}$ were found in $35.7 \%(n=924)$ of the COPD patients and $35.3 \%$ $(n=341)$ of the ACO patients.

Conclusion: In this group of COPD and ACO patients remotely diagnosed by pulmonologists, a substantial proportion would be considered to have asthma characteristics according to the guidelines. This may explain the high number of inhaled corticosteroid (ICS) prescriptions found in primary care COPD patients. Prospective studies are necessary to identify patients who may or may not benefit from ICS containing treatment. Hence, personalized care in primary care can be optimized.

Keywords: chronic obstructive pulmonary disease, asthma COPD overlap, asthma characteristics, guidelines

\section{Introduction}

Chronic Obstructive Pulmonary Disease (COPD) is a chronic obstructive disease characterized by a (progressive) persistent airflow limitation. ${ }^{1}$ COPD is associated with high mortality rates. The mortality rate for Europe is approximately 18 per 100.000 (age-standardized) per year and in the Netherlands it is even higher, at 22.62 men and women per 100.000 per year. $^{2-4}$ There are currently, about 600.000 patients in the Netherlands diagnosed with COPD. ${ }^{5}$

COPD is supposed to be treated according to (inter)national guidelines. These guidelines are based on the classic COPD patient, with bronchodilation as the firstchoice treatment for symptom and exacerbation reduction. ${ }^{1,6}$ Similarly, asthma 
guidelines are based on the classic asthma patient, with inhaled corticosteroids (ICS) as the cornerstone of the treatment. ${ }^{7}$ In COPD, the benefit of ICS containing treatment is debated, and it is only recommended for a specific subgroup of patients. ${ }^{1}$ Despite this, approximately $50 \%$ of the COPD patients in primary care in Europe are treated with ICS containing treatment. ${ }^{8-12}$

Treatments containing ICS are reported to have several benefits for COPD patients. The exacerbation frequency, the number of symptoms, and the number of hospitalizations are all reported to decrease when treating patients with ICS. ${ }^{13-15}$ In addition, withdrawal from ICS containing treatment is reported to cause an increase in symptoms and exacerbations. ${ }^{1}$ However, it has also been shown that long-term use of ICS containing treatment is associated with several side effects, primarily an increased risk of pneumonia, ${ }^{16-18}$ diabetes and its control, ${ }^{19-21}$ and fractures. ${ }^{22}$ In contrast, it is also reported that withdrawal from ICS containing treatment causes no harm to the patients, and that it can reduce the exacerbation rate and the chance of pneumonia. ${ }^{23,24}$ These results indicate that ICS containing treatment may be beneficial for some COPD patients while for other COPD patients it may not. It is therefore of great clinical importance to identify those patients who may benefit from ICS containing treatment and those patients who are at risk for the side effects.

Three patient characteristics have been identified that distinguish the patients most likely to benefit from ICS containing treatment. First, patients who have had one or more exacerbations leading to hospitalization in the last year and patients who have had two or more moderate or severe exacerbations in the last year despite appropriate bronchodilator use. ${ }^{24,25}$ Second, patients with higher blood eosinophil (Eos) counts ( $\geq 300$ cells per $\mu \mathrm{L}$ ). ${ }^{24,26,27}$ Third, patients who have characteristics of asthma. ${ }^{24,25,28,29}$

International guidelines recommend prescribing ICS to COPD patients who comply with one of these tree patient characteristics. $^{1,6,28}$ In contrast, the Dutch General Practitioners (GP) COPD guideline specifies the following asthma characteristics in COPD: history of asthma, symptom pattern typical for asthma, (family) history of atopy or reversibility. COPD patients with one or more of these characteristics can be considered as having asthma and are thus recommended to be treated according to the asthma guidelines, including ICS containing treatment. ${ }^{6}$ Currently, it is unknown what proportion of Dutch COPD patients treated in primary care have such asthma characteristics.
Therefore, this study aims to describe the prevalence of asthma characteristics and high Eos counts in patients with a pulmonologist confirmed working diagnosis of COPD or asthma COPD overlap (ACO) using the dataset of the asthma/COPD (AC) service located in the north of the Netherlands. ${ }^{30}$ In addition, the prevalence of asthma characteristics in COPD and ACO patients with low and high blood eosinophil count is examined.

\section{Patients and Methods Study Design}

This retrospective database study was conducted using the dataset of the AC service. According to Dutch regulations, ethical approval was not required because the data were used anonymously. This study is reported in accordance with the Strengthening the Reporting of Observational Studies in Epidemiology (STROBE) statements guidelines. ${ }^{31}$ The setup of the study was prespecified and registered in the ENCePP register (register reference code: EUPAS27806).

\section{Dataset}

The analysis is based on data collected in the AC service between 2007 and 2017. ${ }^{30}$ The AC service is a structured diagnostic system in which pulmonologists support general practitioners (GPs) in their diagnosis of patients with suspicion of obstructive lung disease. Patients are asked to complete several questionnaires at home including the Clinical COPD Questionnaire (CCQ), ${ }^{32}$ the Asthma Control Questionnaire (ACQ), ${ }^{33}$ and a medical history questionnaire including allergies, medication use, and smoking history. In addition, spirometry and Body Mass Index (BMI) measurements are performed by a technician of the AC service. Pulmonologists assess these data through a protected website and provide the GPs with a working diagnosis and treatment advice. The website only provides the data; it does not provide diagnostic criteria. The pulmonologist's working diagnosis and treatment advice are based on usual care in daily clinical practice, which is based on (inter)national guidelines. GPs can choose to either refer individual patients or refer all patients from their practice who are using respiratory medication to be assessed by the AC service.

In addition, data from routine clinical care laboratory tests (blood samples: Eos and specific immunoglobulin (IgE)), not specifically performed for respiratory conditions, were collected from the patients' clinical records and added to the AC service dataset. 


\section{Study Population}

The study population consisted of patients aged 40 years and older treated in primary care with a working diagnosis of COPD or ACO from a pulmonologist, aged 40 years and older, who visited the AC service for the first time between 2007 and 2017.

\section{Outcome Measures}

\section{Asthma Characteristics}

Asthma characteristics were selected based on the Dutch GP COPD guidelines. ${ }^{6}$ Subsequently, these characteristics were operationalized based on available data in the $\mathrm{AC}$ service dataset (Box 1). Question 1 from the ACQ - "night time awakening", this question is indicating a symptom pattern typical for asthma, was transformed into a binary variable. The cut off was set between 0 ("never") and 1 ("hardly ever"). Several questions from the AC service questionnaires were used to create the atopy variable (Box 1). The scores of all atopy-related questions were calculated and converted into a binary variable distinguishing whether atopy was present or not. The sum of the asthma characteristics represented the total number of asthma characteristics for each patient (Box 1), with a minimum of 0 asthma characteristics a maximum of 4 asthma characteristics.

\section{Blood Eosinophils (Eos)}

The Eos analysis is based on the available data collected between 2007 and 2017. The most recent available Eos data was selected for each patient and split into four categories using the following cut-offs: 1) 0-49 cells per $\mu \mathrm{L}$; 2) 50-100 cells per $\mu \mathrm{L}$; 3) 101-299 cells per $\mu \mathrm{L}$, and 4) $\geq 300$ cells per $\mu \mathrm{L}$. The cutoffs are based on current guideline recommendations and the possible higher risk of adverse events in patients with low eosinophil counts. ${ }^{1,27}$

\section{Statistical Analysis}

Descriptive statistics were used to describe the outcome measures. The baseline characteristics are shown as mean \pm standard deviation or, in the case of non-normally distributed data, median and range. Percentages were used to describe the prevalence of asthma characteristics.

\section{Results}

The initial data set consisted of 19,077 patients. A total of 14,269 patients were excluded because they were younger than 40 years, were not given a respiratory working

Box I Asthma Characteristics as Defined in the Dutch GP COPD Guideline and the Operationalization Based on the Available ACService Data

\begin{tabular}{|c|c|}
\hline According to Dutch GP COPD guideline ${ }^{6}$ & Data available in AC-service data \\
\hline \multicolumn{2}{|l|}{ History of asthma } \\
\hline "Anamnestic suspicion of asthma: a history of asthma" & Patient-reported history of asthma \\
\hline \multicolumn{2}{|l|}{ Symptom pattern } \\
\hline $\begin{array}{l}\text { "Anamnestic suspicion of asthma: the nature of the symptom } \\
\text { pattern" }\end{array}$ & $\begin{array}{l}\text { Question I of the Asthma Control Questionnaire is regarded as the most } \\
\text { typical asthma sign: "Nighttime awakenings" }\end{array}$ \\
\hline \multicolumn{2}{|l|}{ Atopy of the patient or in first-degree family members } \\
\hline $\begin{array}{l}\text { "Anamnestic suspicion of asthma: Atopy of the patient or in } \\
\text { first-degree family members" }\end{array}$ & $\begin{array}{l}\text { A combination of different variables of the data set: } \\
\text { - Self-reported atopy: } \\
\text { P Patient-reported responsiveness for the following triggers: House-dust mites, } \\
\text { food, grass pollen, tree pollen, animal dander, and seasonal change. } \\
\text { - Self-reported history of atopy: } \\
\circ \text { History of: } \\
\circ \text { Allergic Rhinitis } \\
\circ \text { Allergy } \\
\circ \text { Eczema } \\
\text { - Atopy of first-degree family members: Not available in this data set }\end{array}$ \\
\hline \multicolumn{2}{|l|}{ Reversibility } \\
\hline $\begin{array}{l}\text { "Increase in } \mathrm{FEV}_{\text {, of }} \geq 12 \% \text { and } \geq 200 \mathrm{~mL} \text { compared to the } \mathrm{FEV} \text {, } \\
\text { prior to bronchodilatation suggestive for asthma" }\end{array}$ & $\begin{array}{l}\text { Increase in } \mathrm{FEV}_{\text {, of }} \geq 12 \% \text { and } \geq 200 \mathrm{~mL} \text { compared to the } \mathrm{FEV} \text {, prior to } \\
\text { bronchodilatation }\end{array}$ \\
\hline
\end{tabular}

Abbreviations: GP, general practitioner; COPD, chronic obstructive pulmonary disease; AC service, asthma/COPD service; GOLD, Global Initiative for Chronic Obstructive Lung Disease; FEVI, forced expiratory volume in I second. 


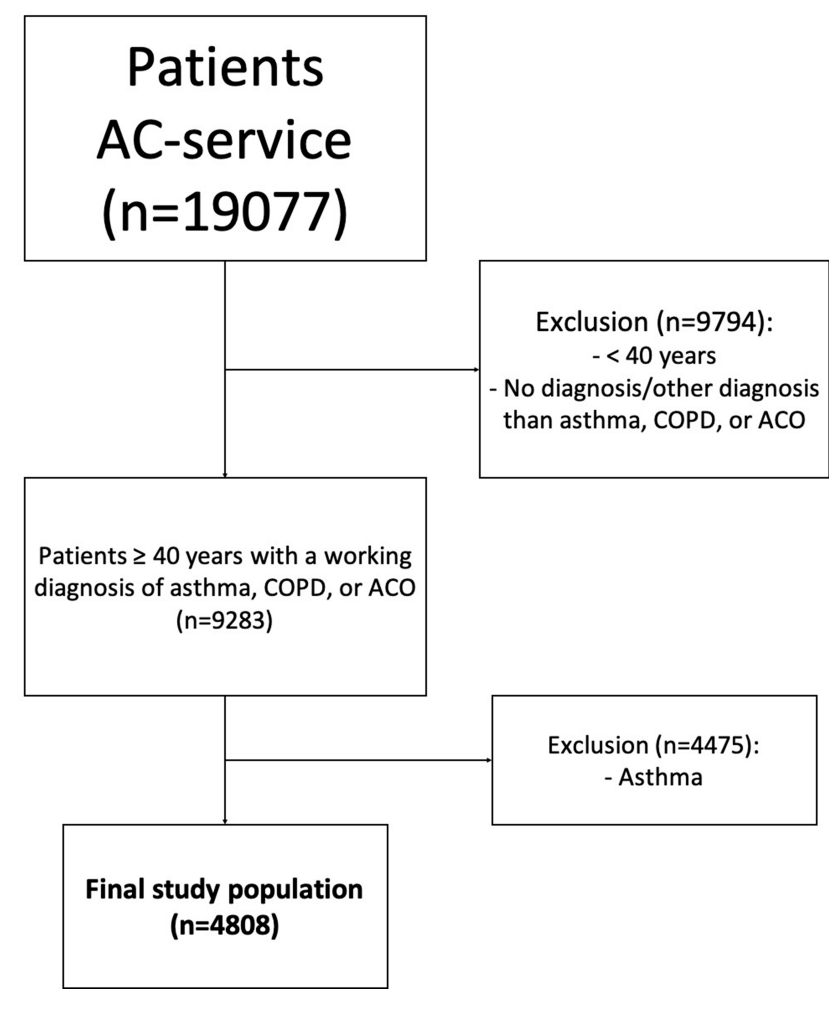

Figure I In- and exclusion flowchart

diagnosis, or their working diagnosis was not COPD or ACO. The final study population consisted of 4808 patients with COPD $(n=3532)$ or ACO $(n=1276)$ (Figure 1).

The median age of the patients was 66 years for COPD patients and 60 years for ACO patients. ICS (either ICS alone or combined with a long-acting bronchodilator) was used by $36.5 \%$ of the COPD patients and $49.6 \%$ of the ACO patients at the baseline visit (Table 1).

\section{Asthma Characteristics}

Of the COPD patients, $65.6 \%(\mathrm{n}=1956)$ had one or more asthma characteristics based on the operationalization of the available AC service data. Of the ACO patients, 90.9\% $(n=1059)$ had one or more asthma characteristics (Figure 2). With regard to individual asthma characteristics (see Figure 3A-D), the most prevalent characteristics were "symptom pattern typical for asthma", which was present in $40.1 \%$ $(n=1401)$ of the COPD patients, and "signs of atopy", which was present in $56.1 \%(\mathrm{n}=716)$ of the ACO patients.

Of the $42.6 \%$ ( $n=1271)$ COPD patients with one asthma characteristic (see Figure 2), the most prevalent characteristic was "symptom pattern typical for asthma", present in 53.1\% $(n=675)$ of the patients (Figure 4). For the 30.6\% $(n=356)$
ACO patients with one asthma characteristic (see Figure 2), the most prevalent characteristic was "signs of atopy", which was present in $40.2 \%(n=143)$ of the ACO patients (Figure 4)

\section{ICS Usage}

Of the COPD patients with no asthma characteristics $10.3 \%(\mathrm{n}=306)$ were using an ICS containing treatment and $22.7 \%(n=684)$ of the COPD patients with asthma characteristics were using an ICS containing treatment. Of the ACO patients with no asthma characteristics, $3.5 \%(\mathrm{n}=142)$ were using an ICS containing treatment and $43.6 \%(n=508)$ of the ACO patients with asthma characteristics were using an ICS containing treatment.

\section{Blood Eosinophil Counts}

Blood eosinophil counts were available for $75.3 \%(n=2661)$ of COPD patients and $75.7 \%(\mathrm{n}=966)$ of ACO patients. Of these patients, $35.7 \%(\mathrm{n}=924)$ of the COPD patients and $35.3 \%(n=341)$ of the ACO patients had an Eos count of over 300 cells per $\mu \mathrm{L}$ (Figure 5). The different Eos counts show no major patterns in the percentage of patients having one or more asthma characteristics for COPD patients (Figure 6A) or for ACO patients (Figure 6B).

No patterns were found based on the Eos counts in the percentage of patients with COPD or ACO having a history of asthma, a symptom pattern typical for asthma, atopy, or reversibility (data not shown). However, $21 \%$ of ACO patients with an Eos count of 0 cells per $\mu \mathrm{L}$ had a history of asthma, whereas $31 \%$ of ACO patients with an Eos count of $\geq 300$ cells per $\mu \mathrm{L}$ had a history of asthma.

\section{Discussion}

The focus of this study is identifying the prevalence of asthma characteristics in COPD and ACO patients, as described in (inter)national guidelines. The descriptive results indicate that about $66 \%$ of the COPD patients and about $90 \%$ of the ACO patients have one or more asthma characteristics. About a third of the COPD and ACO patients had an Eos count of over 300 cells per $\mu \mathrm{L}$. The COPD and ACO patients with high Eos counts did not have more asthma characteristics than patients with low Eos counts, or vice versa.

Of the ACO patients, $90.9 \%$ had one or more asthma characteristics, which corresponds with the clinical picture of ACO in which asthma characteristics are key aspects. ${ }^{28}$ More surprisingly, $65.6 \%$ of the COPD patients had one or more asthma characteristics. This result is in line with several other studies reporting asthma characteristics in 
Table I Baseline Characteristics

\begin{tabular}{|c|c|c|}
\hline & COPD $(\mathrm{N}=3532)$ & $A C O(N=1276)$ \\
\hline $\begin{array}{l}\text { Age, median [IQR] } \\
\text { Gender }(\% \text { male }(n)) \\
\text { BMI, median [IQR] }\end{array}$ & $\begin{array}{l}66.0[59-74] \\
57.2 \%(n=2020) \\
26.0[23-29]\end{array}$ & $\begin{array}{l}60.0[53-69] \\
49.8 \%(n=636) \\
27.0[24-30]\end{array}$ \\
\hline $\begin{array}{l}\text { Age at which lung complaints started }{ }^{\mathrm{a}} \text {, median [IQR] } \\
\text { Age }<5 \text { years, } \%(n) \\
\text { Age } 5-40 \text { years, } \%(n) \\
\text { Age } \geq 40 \text { years }\end{array}$ & $\begin{array}{l}57[45-66] \\
18.6 \%(n=657) \\
10.3 \%(n=364) \\
71.1 \%(n=2511)\end{array}$ & $\begin{array}{l}40[12-55] \\
19.9 \%(n=254) \\
33.5 \%(n=428) \\
46.6 \%(n=594)\end{array}$ \\
\hline $\begin{array}{l}\text { GOLD category }, \%(n) \\
\text { A } \\
\text { B } \\
\text { C } \\
\text { D } \\
\text { Data available }\end{array}$ & $\begin{array}{l}30.3 \%(n=1067) \\
50.7 \%(n=1792) \\
4.9 \%(n=171) \\
14.0 \%(n=495) \\
99.8 \%(n=3525)\end{array}$ & $\begin{array}{l}26.4 \%(n=335) \\
51.3 \%(n=651) \\
5.4 \%(n=68) \\
16.9 \%(n=214) \\
99.4 \%(n=1268)\end{array}$ \\
\hline 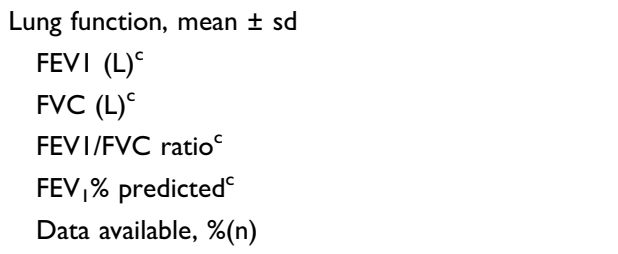 & $\begin{array}{l}1.96 \pm 0.71 \\
3.51 \pm 1.02 \\
55.87 \pm 11.35 \\
66.22 \pm 17.40 \\
99.6 \%(n=3518)\end{array}$ & $\begin{array}{l}2.17 \pm 0.69 \\
3.66 \pm 1.03 \\
59.54 \pm 9.88 \\
70.13 \pm 15.19 \\
99.5 \%(n=1270)\end{array}$ \\
\hline $\begin{array}{l}\text { Respiratory medication }{ }^{\mathrm{d}}, \%(\mathrm{n}) \\
\text { ICS containing treatment } \\
\text { LAMA only (no ICS treatment) } \\
\text { LABA only (no ICS treatment) } \\
\text { LABA/LAMA (no ICS treatment) }\end{array}$ & $\begin{array}{l}36.5 \%(n=1289) \\
10.8 \%(n=383) \\
1.4 \%(n=49) \\
0.5 \%(n=18)\end{array}$ & $\begin{array}{l}49.6 \%(n=636) \\
1.6 \%(n=20) \\
4.9 \%(n=63) \\
0.6 \%(n=8)\end{array}$ \\
\hline $\begin{array}{l}\text { Self-reported exacerbations, \%(n) } \\
\text { None in the last } 12 \text { months } \\
\text { At least one in the last } 12 \text { months } \\
\text { At least two in the last } 12 \text { months } \\
\text { Data available }\end{array}$ & $\begin{array}{l}57.1 \%(n=2015) \\
42.9 \%(n=1511) \\
18.9 \%(n=666) \\
99.8 \%(n=3526)\end{array}$ & $\begin{array}{l}52.4 \%(n=667) \\
47.6 \%(n=607) \\
22.1 \%(n=282) \\
99.8 \%(n=1274)\end{array}$ \\
\hline $\begin{array}{l}\text { Smoking status, } \%(\mathrm{n}) \\
\text { Yes, currently smoking } \\
\text { Yes, but quit } \geq 12 \text { months ago } \\
\text { Never smoked } \\
\text { Data available }\end{array}$ & $\begin{array}{l}48.5 \%(n=1710) \\
47.8 \%(n=1686) \\
3.6 \%(n=128) \\
99.8 \%(n=3524)\end{array}$ & $\begin{array}{l}45.9 \%(n=585) \\
46.2 \%(n=589) \\
7.9 \%(n=101) \\
99.9 \%(n=1275)\end{array}$ \\
\hline $\begin{array}{l}\text { Triggers causing symptoms, \%(n) } \\
\text { Atopy } \\
\text { Hyperreactivity } \\
\text { No triggers }\end{array}$ & $\begin{array}{l}16.4 \%(n=581) \\
35.5 \%(n=1255) \\
37.5 \%(n=1323)\end{array}$ & $\begin{array}{l}40.5 \%(n=517) \\
59.0 \%(n=753) \\
19.7 \%(n=252)\end{array}$ \\
\hline $\begin{array}{l}\text { Specific lgE, \%(n) } \\
\text { Positive screening aero allergens }{ }^{\mathrm{e}} \\
\text { Data available }\end{array}$ & $\begin{array}{l}18.9 \%(n=94) \\
14.2 \%(n=498)\end{array}$ & $\begin{array}{l}28.4 \%(n=75) \\
20.7 \%(n=264)\end{array}$ \\
\hline
\end{tabular}

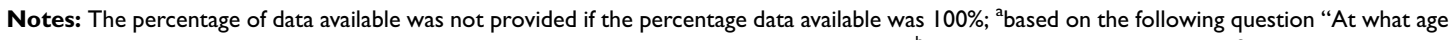
did you experience lung complaints for the first time (coughing, wheezing, breathlessness)"; b based on GOLD 2019-CCQ; 'post-bronchodilator; ${ }^{d}$ short acting bronchodilator use is not taken into account; ${ }^{\text {P }}$ hadiaTop.

Abbreviations: COPD, chronic obstructive pulmonary disease; ACO, asthma COPD overlap; IQR, interquartile range; BMI, body mass index; GOLD, Global Initiative for Chronic Obstructive Lung Disease; FEVI, forced expiratory volume in I second; FVC, forced vital capacity; ICS, inhaled corticosteroids; LAMA, long-acting muscarinic antagonist; LABA, long-acting beta 2 agonist; lgE, immunoglobulin. 


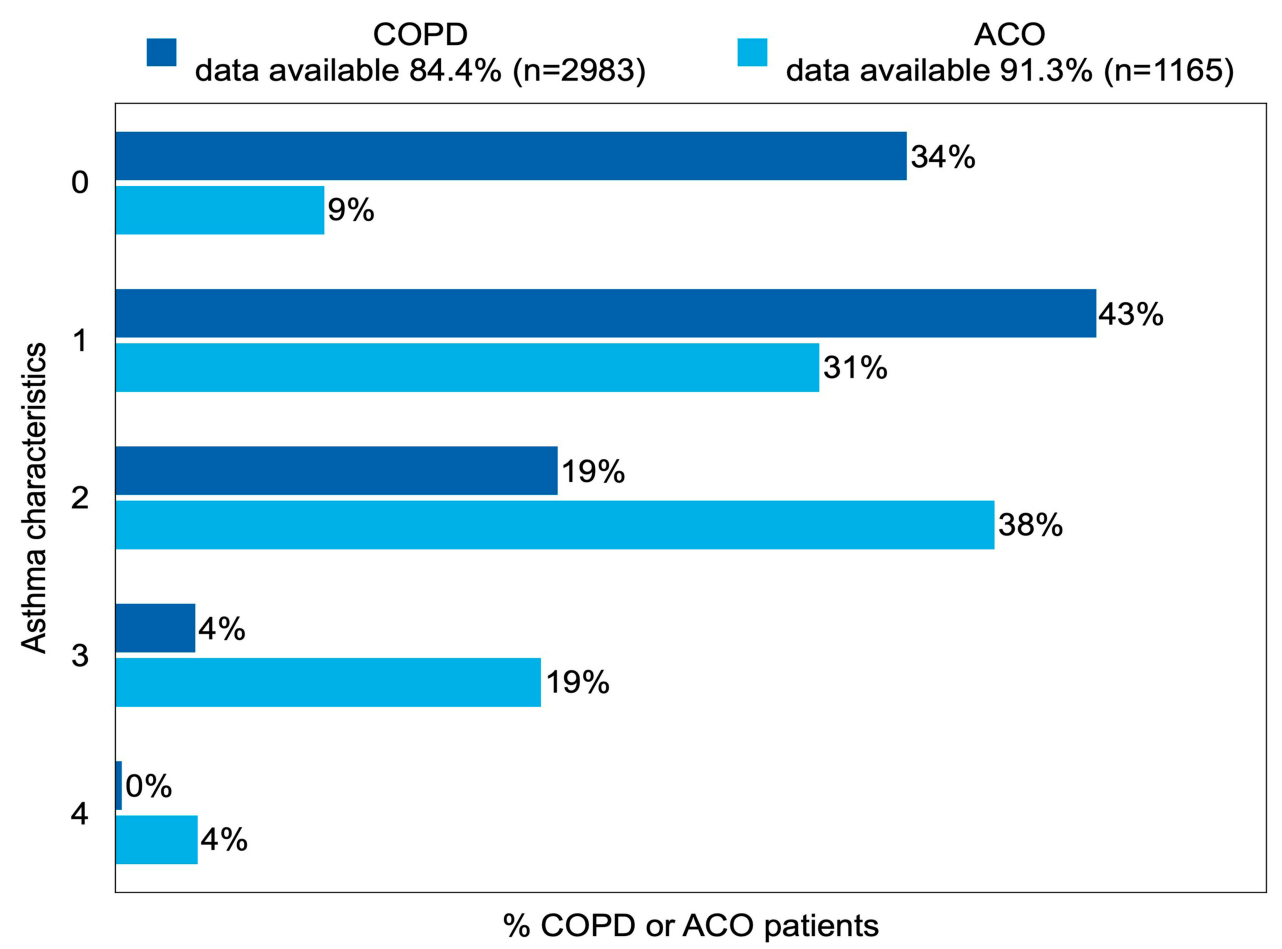

Figure 2 Prevalence of number of asthma characteristics in patients with COPD or ACO. Note: The reported percentages are rounded to whole numbers.
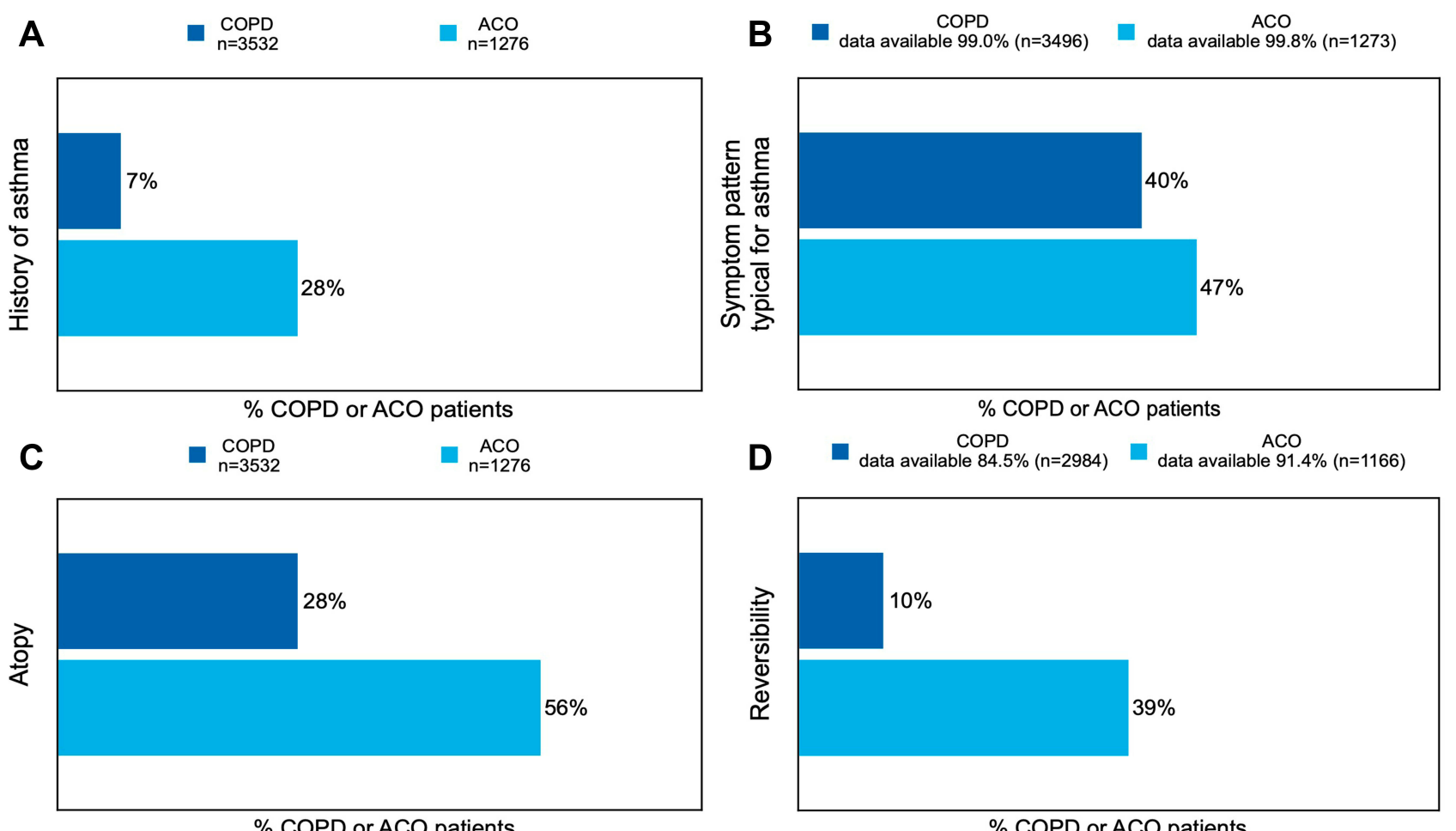

$\%$ COPD or ACO patients



$\%$ COPD or ACO patients

Figure 3 Prevalence of the individual asthma characteristics ((A) history of asthma, (B) symptom pattern typical for asthma, (C) atopy, (D) reversibility) in COPD or ACO patients.

Note: The reported percentages are rounded to whole numbers. 




Figure 4 Prevalence of the individual asthma characteristics in COPD or ACO patients with one asthma characteristic.

Note: The reported percentages are rounded to whole numbers.

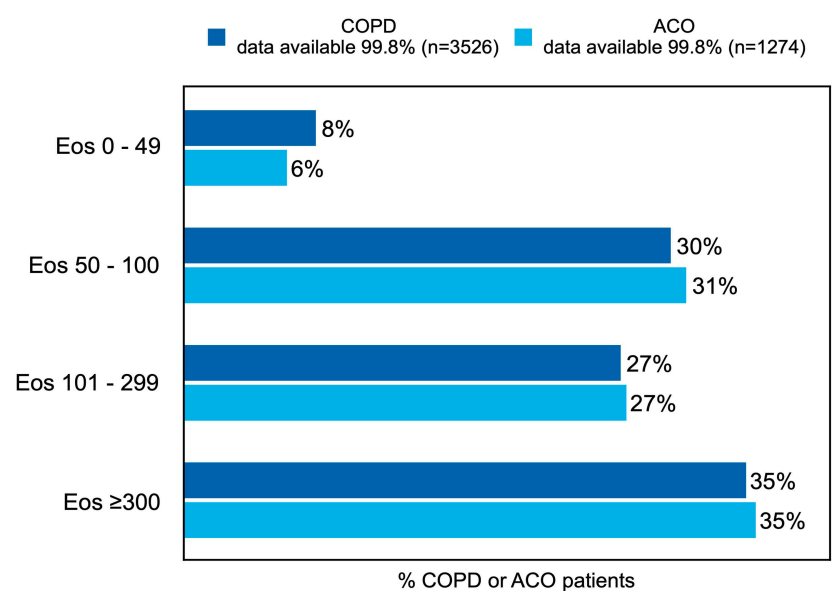

Figure 5 Prevalence of Eos counts in COPD or ACO patients.

Note: The reported percentages are rounded to whole numbers.

Abbreviation: Eos, blood eosinophils; all blood Eos counts are reported in cells per $\mu \mathrm{L}$.

COPD patients, indicating that these characteristics are not exclusive to asthma patients. Silva et al (2004), reported that adults with asthma had a higher risk of developing COPD over time than adults without asthma, ${ }^{34}$ implying that a history of asthma can be found in COPD patients. The joint GOLD and GINA report regarding ACO indicated that the prevalence of atopy in COPD patients is the same as in the normal population. ${ }^{28}$ Tsiligianni et al (2016) reported that night time symptoms are common in COPD patients. ${ }^{35}$ Additionally, Albert et al (2012) reported reversibility in about $16 \%$ of the COPD patients in their study, which is twice as high as the percentage found in our study. ${ }^{36}$
Reversibility of $\geq 12 \%$ and $\geq 200 \mathrm{~mL}$ is common in patients with asthma and patients with COPD, especially in COPD patients with low FEV1; therefore, setting the cutoff at $12 \%$ and $400 \mathrm{~mL}$ for establishing reversibility is more distinctive. ${ }^{28}$ When this advice is applied to our data, the number of COPD patients that classify as reversible drops to $1.1 \%(\mathrm{n}=39)$, and the number of ACO patients drops to $10.2 \%(n=130)$. This result is in line with the findings of Albert et al, who reported reversibility in 5\% of the COPD patients when using the cutoff of $\geq 12 \%$ and $400 \mathrm{~mL} .^{36}$ However, we aimed to describe the prevalence of reversibility in accordance with the Dutch GP COPD guidelines, which reports using $\geq 12 \%$ and $200 \mathrm{~mL}$ as the cutoff.

In this study, a high prevalence of asthma characteristics was found in COPD and ACO patients. This high prevalence might explain the high number of ICS prescriptions in COPD patients found in various studies because GPs following the Dutch GP COPD guideline may consider prescribing ICS containing treatment to these patients. ${ }^{6}$ Additionally, GPs perceive the potential presence of asthma in COPD patients as a key reason to either prescribe or not start withdrawing ICS containing treatments in COPD patients. ${ }^{37}$ Our results show that ICS containing treatment is used by a higher percentage of patients with asthma characteristics than patients without asthma characteristics; however, the percentage does not represent the total number of patients with asthma characteristics.

In the joint GOLD and GINA report, it was proposed that a combination of several criteria/symptoms is needed to identify a COPD patient as asthmatic. ${ }^{28}$ Taking this recommendation into account, a lower proportion of COPD patients would classify as being asthmatic since, in our study, a large proportion had only one asthma characteristic. However, the Dutch GP COPD guideline does not specify the number of asthma characteristics needed to classify a COPD patient as asthmatic. For further revisions of the guideline, therefore, it might be a consideration to more clearly define the (number of) asthma characteristics which really characterize whether a COPD patient should be identified and treated as asthmatic.

In addition, about a third of the COPD and ACO patients in our study had an Eos count of 300 cells per $\mu \mathrm{L}$ or higher. According to the international guidelines, an ICS containing treatment might be considered for these patients. ${ }^{1,16}$ This advice is in accordance with the precision medication strategy of Agusti et al (2016), which proposes to treat patients based on their treatable traits instead of 

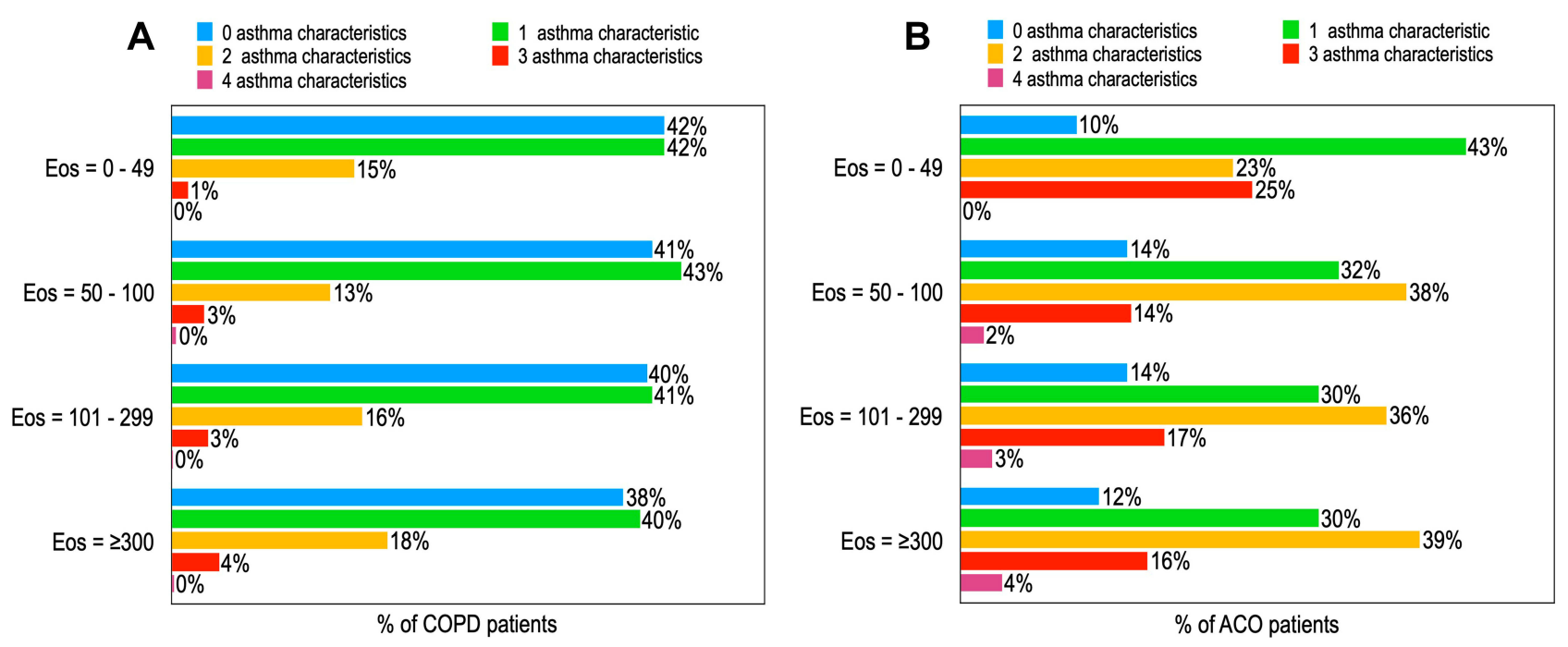

Figure 6 Prevalence of asthma characteristics in COPD (A) or ACO (B) patients sorted by Eos counts.

Note: The reported percentages are rounded to whole numbers.

Abbreviation: Eos, blood eosinophils; all blood Eos cells per $\mu \mathrm{L}$.

their diagnosis. Eosinophilic airway inflammation is regarded as a treatable trait, with ICS as the first-choice treatment. $^{38}$

Our study found that the patients with high Eos counts did not have more asthma characteristics than the patients with low Eos counts, or vice versa. This suggests that the COPD and ACO patients with high Eos counts are not the same patients as those with several asthma characteristics. This result is in line with the advice given in the guidelines for identifying COPD patients who might positively respond to ICS, which is based on whether patients have signs of asthma or whether patients have high Eos counts or recurrent exacerbations. ${ }^{1,16,29}$

This study was conducted in a large primary care population with suspicion of obstructive airway disease from which data is collected in a real-life setting. The application of strict protocols while assessing patients in the AC service resulted in the availability of a high proportion of data. Exceptions are the additional laboratory measures that are not included in the standard AC service protocols, including the specific IgE and Eos counts used in the current study.

This study has some limitations. First of all, the dataset used is not a random sample of patients with ACO and/or COPD in the community. It is the result of ten years of data collection by a strictly protocolled, very practical diagnostic service covering an estimated $70 \%$ of the population in the area where it is active. In this sample, very few patients were previously diagnosed by a specialist in a hospital because in that case a referral to the AC service is not necessary. About $80 \%$ of the patients in the AC service could be diagnosed by the system. ${ }^{30}$

It could be argued that the high number of asthma characteristics in COPD patients found in this study is due to misdiagnosis by the pulmonologist; however, clinical misdiagnosis is unavoidable. Various studies have shown that even very well-informed pulmonologists and GPs may not agree about the differences between asthma, COPD, and ACO. ${ }^{39,40}$ Misdiagnosis could also be the result of the diagnosis being solely based on data alone. However, Lucas et al showed that the agreement between data-based diagnosis and diagnosis when seeing the patient in real life was better than the agreement between pulmonologists. ${ }^{41}$ Additionally, it can also be questioned whether a diagnostic label is really necessary to guide a patient's treatment. The treatable traits paradigm suggests that establishing that a patient probably has a lung disease and subsequently targeting treatment according to the patient's treatable traits may result in better patient management than the current "diagnostic label" based approach. $^{38}$

Furthermore, this study operationalized the asthma characteristics "symptom pattern" using the ACQ question 1 "nighttime awakening". The cutoff for this variable was set between 0 ("never") and 1 ("hardly ever"), thereby making a distinction between patients who experience nighttime awakenings (even if it is hardly ever) and patients who report that they never wake at night. The best placement 
for this cutoff is debatable. The current cutoff might have led to an overestimation of asthma characteristics, and, because the asthma characteristics "symptom pattern" was only represented by nighttime awakening, the overall clinical picture of "symptom pattern" may not be fully taken into account in our study. However, this was the best available variable in our data set for operationalizing "a symptom pattern typical for asthma", and the guidelines indicate that it is a major and distinguishing symptom between COPD and asthma. ${ }^{28,42,43}$

\section{Conclusion}

In this group of COPD and ACO patients diagnosed by pulmonologists in primary care, a substantial proportion would be considered to have asthma characteristics according to the guidelines. This may explain the high number of ICS prescriptions found in primary care COPD patients. However, prospective studies are necessary to identify the number and nature of asthma characteristics that predict a positive response to ICS containing treatment. In this way, patients who may not or may benefit from ICS containing treatment can be correctly identified, leading to more optimized and personalized care for COPD patients in primary care.

\section{Abbreviations}

$\mathrm{AC}$ service, asthma/COPD service; $\mathrm{ACO}$, asthma COPD overlap; ACQ, Asthma Control Questionnaire; BMI, body mass index; CCQ, Clinical COPD Questionnaire; COPD, chronic obstructive pulmonary disease; Eos, blood eosinophils; $\mathrm{FEV}_{1}$, forced expiratory volume in 1 second; GP, general practitioner; ICS, Inhaled corticosteroids; IgE, immunoglobulin; STROBE, Strengthening the Reporting of Observational Studies in Epidemiology.

\section{Acknowledgments}

We would like to thank Rhiannon Bruce for medical writing support.

\section{Author Contributions}

The study was designed by AJB, BMJFdB, EH, RAR, AMMSvdV, EIM, and JWHK. The acquisition of data was performed by AJB, BMJFdB, RAR, EIM, and JWHK. The data were analyzed by AJB and JWHK, and interpreted by AJB, BMJFdB, EH, RAR, AMMSvdV, EIM, and JWHK. The manuscript was drafted by AJB, AJB, BMJFdB, and JWHK and revised for intellectual content and approved for publication by all authors. All authors made substantial contributions to conception and design, acquisition of data, or analysis and interpretation of data; took part in drafting the article or revising it critically for important intellectual content; gave final approval of the version to be published; and agree to be accountable for all aspects of the work.

\section{Funding}

This study is funded by General Practitioners Research Institute and GlaxoSmithKline BV.

\section{Disclosure}

AJB, BMJFdB, EH, EIM, and RAR declare that they have no competing interests. AMMSvdV is a former employee of GSK and currently an employee of Merck Sharp \& Dohme; also reports personal fees from GlaxoSmithKline, during the conduct of the study; personal fees from GlaxoSmithKline, personal fees from MSD, outside the submitted work. JWHK reports grants and personal fees from AstraZeneca, grants and personal fees from Boehringer Ingelheim, grants from Chiesi, grants and personal fees from GSK, grants and personal fees from Novartis, grants from Mundi Pharma, and grants from TEVA, outside the submitted work. The authors report no other conflicts of interest in this work.

The abstract of this paper was presented at the ERS International Congress as a conference talk with interim findings. The abstract was published online as an "ERS International Congress abstract" in the European Respiratory Journal: DOI: 10.1183/13993003.congress-2019.OA256

In addition, the abstract of this paper was presented at the Week van de Longen as a poster talk with preliminary findings and the abstract was published online: https:// www.weekvandelongen.nl/nl/abstracts/prevalence-ofasthma-characteristics-in-copd-patients-in-a-dutch-wellestablished-asthmacopd-service-for-primary-care.

\section{References}

1. Global Initiative for Chronic Obstructive Lung Disease. Global Strategy for the diagnosis, management, and prevention of chronic obstructive pulmonary disease. Am J Respir Crit Care Med. 2019.

2. López-Campos JL, Ruiz-Ramos M, Soriano JB. Mortality trends in chronic obstructive pulmonary disease in Europe, 1994-2010: a joinpoint regression analysis. Lancet Respir Med. 2014;2(1):54-62. doi:10.1016/S2213-2600(13)70232-7

3. Lopez AD, Shibuya K, Rao C, et al. Chronic obstructive pulmonary disease: current burden and future projections. Eur Respir J. 2006;27 (2):397-412. doi:10.1183/09031936.06.00025805

4. European Respiratory Society. Chronic Obstructive Pulmonary Disease; White Book Chapter 13. 
5. Poos MJJC, Nielen MMJ Prevalentie en nieuwe gevallen van COPD. 2019. Available from: https://www.volksgezondheidenzorg.info/ onderwerp/copd/cijfers-context/huidige-situatie\#!node-prevalentie-en -nieuwe-gevallen-van-copd. Accessed 17 April 2019.

6. Snoeck-Stroband JB, Schermer TRJ, Van Schayck CP, et al. NHGStandaard COPD (Derde Herziening). 2015.

7. Global Initiative for Asthma (GINA). Global Strategy for Asthma Management and Prevention; 2016.

8. Price DB, West D, Gruffydd-Jones K, et al. Management of COPD in the UK primary-care setting: an analysis of real life prescribing patterns. Int J Chronic Obstruct Pulmon Dis. 2014;9:889-905. doi:10.2147/COPD.S62750

9. Bloom CI, Elkin SL, Quint JK. Changes in COPD inhaler prescriptions in the united kingdom, 2000 to 2016. Int $J$ COPD. 2019;14:279-287. doi:10.2147/COPD.S190086

10. Geraets I, SchermerT, KocksJWH, Akkermans R, Bischoff E, van den Bemt L. Primary care cohort study in the sequence of diagnosing chronic respiratory diseases and prescribing inhaled corticosteroids. NPJ Prim Care Respir Med. 2018;28:3-4. doi:10.1038/s41533-0180071-0

11. Lambooij A, Metz de J, Essink R, et al. Medicatie bij Astma en COPD: voorschrijvenen gebruik in de eerste lijn. 2016.

12. Sulku J, Janson C, Melhus H, et al. A cross-sectional study assessing appropriateness of inhaled corticosteroid treatment in primary and secondary care patients with COPD in Sweden. Int $J$ COPD. 2019;14:2451-2460. doi:10.2147/COPD.S218747

13. Lipson DA, Barnacle H, Birk R, et al. FULFIL trial: once-daily triple therapy for patients with chronic obstructive pulmonary disease. Am $J$ Respir Crit Care Med. 2017;196(4):438-446. doi:10.1164/ rccm.201703-0449OC

14. Lipson DA, Barnhart F, Brealey N, et al. Once-daily single-inhaler triple versus dual therapy in patients with COPD. $N$ Engl J Med. 2018;378:1671-1680. doi:10.1056/NEJMoa1713901

15. Papi A, Vestbo J, Fabbri L, et al. Extrafine inhaled triple therapy versus dual bronchodilator therapy in chronic obstructive pulmonary disease (TRIBUTE): a double-blind, parallel group, randomised controlled trial. Lancet. 2018;391:1076-1084. doi:10.1016/S01406736(18)30206-X

16. Kaplan AG, Roman-Rodriguez M, Price DB, Tsiligianni I. Appropriate use and withdrawal of inhaled corticosteroids in patients with COPD. 2014. NPJ Prim Care Respir Med.

17. Yawn BP, Li Y, Tian H, Zhang J, Arcona S, Kahler KH. Inhaled corticosteroid use in patients with chronic obstructive pulmonary disease and the risk of pneumonia: a retrospective claims data analysis. Int J COPD. 2013;8:295-304. doi:10.2147/COPD.S42366

18. Suissa S, Patenaude V, Lapi F, Ernst P. Inhaled corticosteroids in COPD and the risk of serious pneumonia. Thorax. 2013;68 (11):1029-1036. doi:10.1136/thoraxjnl-2012-202872

19. Ajmera M, Shen C, Sambamoorthi U. Concomitant medication use and new-onset diabetes among medicaid beneficiaries with chronic obstructive pulmonary disease. Popul Health Manag. 2017;20: 224-232. doi:10.1089/pop.2016.0047

20. Suissa S, Kezouh A, Ernst P. Inhaled corticosteroids and the risks of diabetes onset and progression. Am J Med. 2010;123(11):1001-1006. doi:10.1016/j.amjmed.2010.06.019

21. Price DB, Russell R, Mares R, et al. Metabolic effects associated with ICS in patients with COPD and comorbid type 2 diabetes: a historical matched cohort study. PLoS One. 2016;11(9):1-17. doi:10.1371/journal.pone. 0162903

22. Loke YK, Cavallazzi R, Singh S. Risk of fractures with inhaled corticosteroids in COPD: systematic review and meta-analysis of randomised controlled trials and observational studies. Thorax. 2011;66(8):699-708. doi:10.1136/thx.2011.160028

23. Suissa S, Coulombe J, Ernst P. Discontinuation of inhaled corticosteroids in COPD and the risk reduction of pneumonia. Chest. 2015;148(5):1177-1183. doi:10.1378/chest.15-0627
24. Agusti A, Fabbri LM, Singh D. et al. Inhaled corticosteroids in COPD: friend or foe? Eur Respir J;2018. 1801219. doi:10.1183/ 13993003.01219-2018

25. Kaplan AG, Fabbri LM, Singh D. Applying the wisdom of stepping down inhaled corticosteroids in patients with COPD: a proposed algorithm for clinical practice. Int J COPD. 2015;10:2535-2548. doi:10.2147/COPD.S93321

26. Watz H, Tetzlaff K, Wouters EFM, et al. Blood eosinophil count and exacerbations in severe chronic obstructive pulmonary disease after withdrawal of inhaled corticosteroids: a post-hoc analysis of the WISDOM trial. Lancet Respir Med. 2016;4(5):390-398. doi:10.10 16/S2213-2600(16)00100-4

27. Bafadhel M, Peterson S, De Blas MA, et al. Predictors of exacerbation risk and response to budesonide in patients with chronic obstructive pulmonary disease: a post-hoc analysis of three randomised trials. Lancet Respir. Med. 2018;6(2):117-126. doi:10.1016/S2213-2600(18)30006-7

28. Global Initiative for Chronic Obstructive Lung Disease. Diagnosis of Diseases of Chronic Airflow Limitation: Asthma, COPD and Asthma - COPD Overlap Syndrome (ACOS); 2015.

29. Leung JM, Sin DD. Inhaled corticosteroids in COPD: the final verdict is .... Eur Respir J. 2018;52:1801940. doi:10.1183/13993003.01940-2018

30. Metting EI, Riemersma RA, Kocks JWH, Piersma-Wichers MG, Sanderman R, Van Der Molen T. Feasibility and effectiveness of an Asthma/COPD service for primary care: a cross-sectional baseline description and longitudinal results. NPJ Prim Care Respir Med. 2015;25(1):1-7. doi:10.1038/npjpcrm.2014.101

31. von Elm E, Altman DG, Egger M, Pocock SJ, Gøtzsche PC, Vandenbroucke JP. The strengthening the reporting of observational studies in epidemiology (STROBE) statement: guidelines for reporting observational studies. Int $J$ Surg. 2014;12:1495-1499. doi:10.1016/j.ijsu.2014.07.013

32. van der Molen T, Willemse BWM, Schokker S, Ten Hacken NHT, Postma DS, Juniper EF. Development, validity and responsiveness of the clinical COPD questionnaire. Health Qual Life Outcomes. 2003;1 (1):1-10. doi:10.1186/1477-7525-1-13

33. Juniper EF, Bousquet J, Abetz L, Bateman ED. Identifying 'wellcontrolled' and 'not well-controlled' asthma using the Asthma Control Questionnaire. Respir. Med. 2006;100(4):616-621. doi:10. 1016/j.rmed.2005.08.012

34. Silva GE, Sherrill DL, Guerra S, Barbee RA. Asthma as a risk factor for COPD in a longitudinal study. Chest. 2004;126(1):59-65. doi:10.1378/chest.126.1.59

35. Tsiligianni I, Metting E, Van Der Molen T, Chavannes N, Kocks JWH. Morning and night symptoms in primary care COPD patients: a cross-sectional and longitudinal study. An UNLOCK study from the IPCRG. NPJ Prim Care Respir Med. 2016;26(1):1-8. doi:10.1038/npjpcrm.2016.40

36. Albert P, Agusti A, Edwards L, et al. Bronchodilator responsiveness as a phenotypic characteristic of established chronic obstructive pulmonary disease. Thorax. 2012;67(8):701-708. doi:10.1136/thoraxjnl-2011-201458

37. De Jong C, Van Boven J, Schermer T, et al. Why prescribe ICS to Dutch COPD patients in primary care, and when and how to stop. Data from focus groups with patients and health care providers. Gen Pract Prim Care. 2018;52:PA917.

38. Agusti A, Bel E, Thomas M, et al. Treatable traits: toward precision medicine of chronic airway diseases. Eur. Respir. J. 2016;47 (2):410-419. doi:10.1183/13993003.01359-2015

39. Jenkins C, FitzGerald JM, Martinez FJ, et al. Diagnosis and management of asthma, COPD and asthma-COPD overlap among primary care physicians and respiratory/allergy specialists: a global survey. Clin. Respir. J. 2019;13(6):355-367. doi:10.1111/crj.13016

40. Lucas AE, Smeenk FJ, van den Borne BE, Smeele IJ, van Schayck OC. Diagnostic assessments of spirometry and medical history data by respiratory specialists supporting primary care: are they reliable? Prim. Care Respir. J. 2009;18(3):177-184. doi:10. 3132/pcrj.2009.00002 
41. Lucas A, Smeenk FJWM, Brouwer T, Smeele I, Brouwer T. The validity of diagnostic support of an asthma/COPD service in primary care. Br J Gen Pract. 2007;57(544):892-896. doi:10.3399/09601 6407782317883
42. Global Initiative for Asthma. Pocket Guide for Asthma Management and Prevention. Global Initiative for Asthma; 2019.

43. Smeele I, Barnhoorn MJM, Broekhuizen BDL, et al. NHG-Standaard Astma Bij Volwassenen (Derde Herziening). 2015.

International Journal of Chronic Obstructive Pulmonary Disease

\section{Publish your work in this journal}

The International Journal of COPD is an international, peer-reviewed journal of therapeutics and pharmacology focusing on concise rapid reporting of clinical studies and reviews in COPD. Special focus is given to the pathophysiological processes underlying the disease, intervention programs, patient focused education, and self management protocols. This journal is indexed on PubMed Central, MedLine and CAS. The manuscript management system is completely online and includes a very quick and fair peer-review system, which is all easy to use. Visit http://www.dovepress.com/testimonials.php to read real quotes from published authors. 